NEWS, VIEWS, AND COMMENTS

\title{
Teaching About Twins: College Courses and Public Lectures/Twin Research: Obesity Control, Post-Zygotic Mutation, In Vitro Fertilization, and Schisis-Associated Defects/Noted in the News: Double Rape Charges, Chinese Twins Separated at Birth, Twin CEO, and Shared Professions
}

\author{
Nancy L. Segal \\ Department of Psychology, California State University, Fullerton, CA, USA \\ The present article describes teaching experiences and observations in college courses and public lectures \\ on twins. It is concluded that much more information about twins, at both research and practical levels, \\ requires general dissemination. This discussion is followed by reviews of recent twin research on the topics \\ of obesity control, post-zygotic mutation, in vitro fertilization, and schisis-associated defects. Media reports \\ of twins accused of rape, infant Chinese twins sold separately for profit, a twin CEO, and twins pursuing \\ the same career are presented.
}

\section{Teaching About Twins: College Courses and Public Lectures}

In recent years, twin research has become a vital part of numerous disciplines outside the more traditional areas of psychology and health. Examples include political views, sports medicine, and game theory (see Segal, 2012; Segal et al., in press). Twinning rates have also escalated dramatically in Western nations - in 2009, in the United States, approximately one in 30 newborn infants were twins, as compared with one in 53 in 1980 (Martin et al., 2012). Based on my experiences with university teaching and public lecturing, it is clear that interest and fascination with twins remain high. It is also surprising and unsettling that among students and the general public, relatively little is known about the biological and psychological aspects of twinning.

Teaching about twins is most successful when lectures are combined with film clips or televised programs con- cerning twin research. Most viewers know at least one twin pair and are able to relate to twinning on a personal level. The difficulty is that this known single set is often viewed as representative of all pairs. Once people understand the various twin designs and research findings, they are better able to place the twins they know into a broader context. Studying film clips and other media conveys twins' behavioral and physical similarities and differences in ways that are meaningful and memorable.

Entertaining questions and comments during informal sessions reveal a great deal of misinformation and

ADDRESS FOR CORRESPONDENCE: Nancy L. Segal, Department of Psychology, California State University, Fullerton, CA 92834, USA. E-mail: nsegal@fullerton.edu 
misconception about twins, even among educated audiences. A frequent misconception is the belief that two placentae necessarily signify dizygotic (DZ) twins, whereas one placenta necessarily indicates monozygotic (MZ) twins. It is well known among twin researchers that virtually all DZ twins have two separate placentae, but in $42 \%$ of the pairs the placentae become fused. Similarly, only about one-third of twins in MZ pairs each have a separate placenta, whereas $43 \%$ of two-chorion MZ pairs show fused placentae. These statistics were reported as early as 1970 by Bulmer in his book, The Biology of Twinning in Man. Lack of knowledge in this area has caused many parents to feel uncertain as to their twins' true zygosity. For example, parents of MZ twins with separate placentae often believe that their children are not identical, despite their awareness of how much their two children look and behave alike. Parents are not the only people who are challenged in this way. I have also lectured to college level students and faculty who report that their 'non-identical' twin friends and colleagues look exactly alike.

Another curious and common theme is the idea that MZ twins, despite their genetic identity, are completely different in every way. Perhaps such views reflect expectations of, and appreciation for, individual differences in behavior. Such views may also reflect the fact that when twins are well known to family and friends their subtle differences become more apparent, leading to errors in judgments of zygosity. I still believe that people meeting twins on a single occasion are better judges of twin type than those who have known them all their lives. It is certain that the late distinguished twin researcher James Shields would agree; see Race \& Sanger (1975).

The press sometimes reports twin research findings in ways that can be misconstrued. Several years ago, at a gathering of parents of twins, a mother asked if half of all twins are homosexual. She had learned from the news that the genetic contribution to male sexual orientation was approximately $50 \%$. (This figure has been revised downward, to $34-39 \%$, due to findings from a large population-based Swedish study; see Gewin, 2013; Långström et al., 2010). I explained that homosexuality was not any more frequent among twins than non-twins and provided a short lesson in interpreting heritability estimates.
The notion that twin births skip generations has been perpetuated for many years. It is conceivable that this can occur in some families, but it is not a rule. The genetic bases of twinning are complex and continue to be the focus of numerous research efforts. The conventional wisdom is that DZ twinning has a genetic component, whereas MZ twinning does not. However, the possibility that MZ twinning may have a partial genetic basis, perhaps in selected families and/or populations, has been raised in recent years (Lichtenstein et al., 1996; see also Gewin, 2013).

Mirror-imaging effects that occur among approximately $25 \%$ of $\mathrm{MZ}$ twin pairs are also poorly understood. The frequently applied label 'mirror-image' twin is erroneous because mirror-imaging refers to reversals in selected traits only. Such traits may include, but are not limited to, hand preference, dermatoglyphic characteristics, hair whorl, birthmarks, and moles and dental patterns. It is not the case that one twin is the perfect mirror-image reversal of the co-twin as some have supposed. Mirrorimaging is associated with delayed splitting of the zygote and is typically seen in conjoined twins whose separation is late and incomplete. Which traits and how many may show mirror-image reversal are most likely a function of the timing of the split and other events at the cellular level.

Space precludes discussion of other common misconceptions surrounding twinning, such as the idea that each pair includes a 'good' twin and an 'evil' twin; that there exists a parapsychological connection between mostly $\mathrm{MZ}$ twins; and that reared apart twins and individuals who lost a twin before or during birth have an intrauterine knowledge of their multiple birth status. Perhaps, it is easier to comprehend twins' fascinating behaviors with reference to these everyday explanations. However, such explanations are neither informative nor helpful if they lack a basis in scientific research. It would be desirable for twin researchers to become increasingly involved in presenting their findings to students and to the public in clear and comprehensible ways. The 2014 meeting of the International Society for Twin Studies, in Budapest, Hungary, would be an excellent forum for thinking creatively about how this goal can be accomplished.

\section{Twin Research}

\section{Obesity Control}

Recent research from Washington University in St. Louis has identified new directions for obesity control (Ridaura et al., 2013). Four pairs of female twins (one MZ and three DZ) discordant for obesity were identified from the Missouri
Adolescent Female Twin Study. Obesity discordance was defined as a body mass index (BMI) difference of greater than $30 \mathrm{~kg} / \mathrm{m}^{2}$ with a continued multiyear difference greater than or equal to $5.5 \mathrm{~kg} / \mathrm{m}^{2}$. Fecal material from obese co-twins was introduced into mice, resulting in significantly greater 
weight gain and fat deposits in those animals, relative to animals receiving fecal matter from their lean co-twins. These findings suggest that modifications in the microbiome underlie changes in body shape and metabolism, thereby suggesting innovative methods for human obesity control. Another intriguing finding was that cohousing mice that had received fecal matter from obese and lean twins prevented the development of increased fat deposits and body size in the former.

This study raises many important questions: What causes some identical twins to have different gut bacteria? How rare are such pairs among identical twins generally? Why were only female twins used as fecal donor? This work should encourage further efforts so that answers to these questions will be forthcoming; see Segal (2013).

\section{Post-Zygotic Mutation}

Post-zygotic mutation as an explanation for the first reported occurrence of $\mathrm{MZ}$ twin discordance for port wine stains (PWS) is of interest (Chen et al., 2013). PWS are cutaneous lesions that are red or purple, and flat or thick. They typically occur in regions around the face and neck. Chen et al. describe two pairs of $\mathrm{MZ}$ twins, one male and one female, in which one co-twin is affected with PWS. In both cases, their families showed no history of the condition. It was suggested that post-zygotic mutation (change in DNA following fertilization) was responsible for the discordance in both twin pairs. This reasoning was based on the pairs' lack of family history, and the parents' recall that the twins were monochorionic-diamniotic pairs. Monochorionic-diamniotic MZ twins are thought to result from zygotic splitting occurring at or about days 4 to 8 , postconception.

Unfortunately, the investigators were unable to confirm the parents' reports of the twins' placentation, information that would also bear upon their proposed explanation of the PWS discordance. Nevertheless, this report is of interest and should encourage additional studies to identifying the source of the twins' difference.

\section{In Vitro Fertilization}

It is well know that in vitro fertilization (IVF) has lead to a dramatic increase in the twinning rates of most Western nations. A recent Australian study showed that the number of twins born in that nation increased from 2,420 in 1983 to 4,458 in 2010 . In 2002, nearly $25 \%$ of Australian twin births were associated with IVF (Umstad et al., 2013). The purpose of the study was to assess the impact of single embryo transfer (SET) on the rate of multiple births. SET has become increasingly practiced by physicians, but on a voluntary basis.

Data were gathered from the Australian Bureau of Statistics and the National Perinatal Data Collection. Data on multiple births conceived following assisted reproductive technology (ART) were obtained from the Australian and New Zealand Assisted Reproductive Database. International data came from the office for National Statistics in England and Wales, as well as the United States National Center for Health Statistics. Analyses showed that twin deliveries from ART fell from 210.4/1,000 in 2001 to 84.3/1,000 in 2009. In 2009, ART twin deliveries represented just $16 \%$ of twin births from $3 \%$ of conceptions, as compared with nearly $25 \%$ of twin births in 2002. The investigators concluded that while multiple births are multifactorial in origin, the implementation of a voluntary SET policy effectively reduced the number of twin births from ART.

\section{Schisis-Associated Defects}

'Schisis' is a medical term that refers to the breaking up of attachments or adhesions (Merriam-Webster Dictionary, 2013). A recent case report described DZ opposite-sex cotwins concordant for bilateral cleft lip and palate (CL/P), but discordant for spina bifida (Kutuk et al., 2013). Kutuk et al. are from the Department of Obstetrics and Gynecology at Erciyes University, Koyseri, Turkey. According to the investigators, schisis theory suggests that neural tube defects and CL/P, as well as some rare hernias, appear to be associated with one another. However, it is rare to see such defects in both members of a DZ twin pair in conjunction with other schisis-related and non-related defects. The schisis association is more frequent in females than in males ( sex ratio $=0.33$ ) and occurs in approximately $4.6 \%$ of twins. (The authors note that small studies suggest an increased frequency for twins, but larger studies do not.) Mothers carrying affected pairs have an elevated miscarriage rate, with $3.7 \%$ of schisis-type abnormalities found in siblings of the probands.

The 24-year-old mother of the affected DZ twins had been referred for medical examination at 21 weeks postconception, 2 days prior to an eventual miscarriage. Ultrasound revealed that the male twin had bilateral CL/P and a single umbilical artery. The female co-twin also showed bilateral $\mathrm{CL} / \mathrm{P}$, in addition to open lumbar spina bifida and oligodactyly (less than the normal number of toes) of both lower limbs. The family had no history of such defects, nor was there consanguinity, exposure to radiation, or taking of potentially harmful drugs. The particular suite of defects seen in this pair was explained by the schisisassociation hypothesis - a common blastogenic event resulting in a schisis complex. Kutuk et al. (2013) note that while polydactyly (more than the normal number of toes and fingers) co-occurs with $\mathrm{CL} / \mathrm{P}$, this case study reported the first co-occurrence of schisis defects and oligodactyly. They recommend ultrasound examinations of dichorionic twin pregnancies to detect possible abnormalities in both fetuses. 


\section{Noted in the News}

\section{Double Rape Charges}

One or both members of an identical twin pair, Mohammed and Aftab Asghar, were linked to the crime of rape in the United Kingdom, based on DNA analyses (Silverman, 2013). This case occurred in November 2011, in Reading Crown Court, Berkshire, but has attracted renewed interest because a trial date has been set for December 2, 2013. Its unusual legal significance and general interest come from the fact that it is impossible to know if one or both of the 22-year-old twin brothers were involved - and if only one, which one? The twins have been granted conditional bail until the court date. A similar case was reported in February 2013 in Marseilles.

\section{Chinese Twins Separated at Birth}

Chinese obstetrician Zhang Shuxia was arrested in July 2013 for selling babies delivered by her patients (Demick, 2013). The 55 -year-old physician obtained the babies by convincing the new mothers and fathers that their infants were deceased, dying, or affected by an incurable condition. China is a nation that prizes male babies, explaining why many stolen males infants were sold to couples wanting sons or having difficulty in conceiving. A national effort to locate these babies, put into effect in 2009, has rescued 54,000 children. Among the rescued children was a pair of female twins (born at Zhang Shuxia's hospital in Fuping), sold separately for slightly reduced fees because of the preference for male infants.

Hundreds of thousands of female infants in China have been abandoned owing to that nation's One-Child Policy and favoring of male children. Among the female infants are twins, some of whom have been adopted together, but some of whom have been adopted apart. These twins can be found in countries around the world. My ongoing studies of these cases now include 43 pairs of twins adopted together by American couples and 15 pairs of twins adopted apart (Segal et al., 2011). Most reared-apart Chinese twins were adopted by families living in the same country, but the members of one pair reside in the United States and Norway. Despite their separation by distance and language, the young twins have been able to spend time together because their parents appreciate the importance of twinship in their children's lives.

\section{Twin CEO}

Glenn Kelman is the CEO of Redfin, an online site for real estate (Bryant, 2013). His career path to that profession was indirect, following application to graduate school, acceptance into medical school, and thoughts about writing and investment banking. He began delivering packages when he ran out of money, then met people who were starting a software company. He took part in that venture and discovered that he enjoyed the work atmosphere immensely. Kelman eventually became connected to Redfin and is now its CEO. At Redfin, one of his main projects is to 'unite real estate agents and software engineers' (p. 2).

Kelman explains his current job satisfaction with reference to being an identical twin. He and his twin formed an 'unassailable force' that gave him the confidence to be different. He and his brother were both somewhat 'different' from other people, so they were not concerned with fitting in - they had each other. Kelman claims that the corporate world is very much in need of people with 'personality', even if they are a little bit different from the rest. He believes this is the reason for his business success.

Interestingly, Kelman did not mention his twin brother by name, nor describe what his brother does for a living. Most identical twins would do that - but Kelman is different.

\section{Shared Professions}

Identical twins, Kristyn and Kellie Wilson, currently attend Paul Mitchell: The School Costa Mesa, for training in hair styling (Hardesty, 2013). The 19-year-old twins were born 2 months premature, weighing 4 pounds (Kristyn) and 3 pounds (Kellie). Kristyn is left-handed and parts her hair on the right side, while Kellie is right-handed and parts her hair on the left side. The twins work together, sharing the tasks of drying, straightening, and styling hair while positioning themselves on different sides of their client. They hope to jointly own and operate a hair salon of their own in the next 5 years.

The twins admit to being somewhat competitive with one another, but did not elaborate on this point. Most importantly, their shared professional interests and talents are consistent with the twin literature on job characteristics (motor skills, complexity, and physical demands), as well as job satisfaction (Arvey et al., 1989). Their future plans for a salon may distinguish them in an industry in which many do not succeed.

\section{References}

Arvey, R. D., Bouchard, T. J., Segal, N. L., \& Abraham, L. M. (1989). Job satisfaction: Environmental and genetic components. Journal of Applied Psychology, 74, 187-192. 
Bryant, A. (2013, August 25). Be yourself, even if you're a little goofy. New York Times (Business), p. 2.

Bulmer, M. G. (1970). The biology of twinning in man. Oxford, UK: Oxford University Press.

Chen, X. D., Hu, X. J., Ma, G., \& Lin, X. X. (2013). Monozygotic twins discordant for port wine stains support the postzygotic mutation hypothesis. Clinical Genetics, 83, 397-398.

Demick, B. (2013, August, 17). She said the baby couldn't survive. Los Angeles Times, p. A1-4.

Gewin, V. (2013). Turning point: Bruno reversade. Nature, 495, 401.

Hardesty, G. (2013, September 19). Two scissors, one dream. Orange County Register, p. 1, 12.

Kutuk, M. S., Ozgun, M. T., Uludag, S., Akgun, H., \& Balta, B. (2013). A case of dichorionic twin pregnancy concordant for bilateral cleft lip and palate and discordant for spina bifida; Schisis association. Fetal and Pediatric Pathology, 32, 371-374.

Långström, N., Rahman, O., Carlström, E., \& Lichtenstein, P. (2010). Genetic and environmental effects on same-sex sexual behavior: A population study of twins in Sweden. Archives of Sexual Behavior, 1, 75-80.

Lichtenstein, P., Olaussen, P. O., \& Källén, A. B. (1996). Twin births to mothers who are twins: A registry-based study. British Medical Journal, 312, 879-881.

Martin, J. A., Hamilton, B. E., \& Osterman, M. J. K. (2012, January). Three decades of twin births in the United States, 1980-2009. NCHS Data Brief, 80, 1-8.

Merriam-Webster Dictionary. (2013). 'Schisis'. Retrieved from http://www.merriam-webster.com/medical/-schisis.
Race, R. R. \& Sanger, R. (1975). Blood groups in man. Oxford: Oxford University Press.

Ridaura, V. K., Faith, J. L., Rey, F. E., Cheng, J., Duncan, A. E., Kau, A. L., . . . Gordon, J. I. (2013). Gut microbiota from twins discordant for obesity modulate metabolism in mice. Science, 341, 1079-1089.

Segal, N. L. (2012). Born together — reared apart: The landmark Minnesota Twin Study. Cambridge, MA: Harvard University Press.

Segal, N. L. (2013). Comment: Ridaura, Faith, Rey, Cheng, Duncan, Kau, et al. (2013). Gut microbiota from twins discordant for obesity modulate metabolism in mice. Science, http://comments.sciencemag.org/content/10.1126/science. 1241214.

Segal, N. L., Munson, J. E., Marelich, W. D., Goetz, A. T., \& McGuire, S. A. (in press). Meeting of minds: Tacit coordination in monozygotic and dizygotic adolescent and adult twins. Personality and Individual Differences.

Segal, N. L., Stohs, J. H., \& Evans, K. (2011). Chinese twin children reared apart and reunited: First prospective study of co-twin reunions. Adoption Quarterly, 14, 61-78.

Silverman, R. (2013, August 20). Identical twins both charged with rape because prosecutors couldn't tell their DNA apart. Retrieved from http://www.businessinsider.com/identicaltwins-both-charged-with-rape-because-prosecutorscouldnt-tell-their-dna-apart-2013-8?IR=T.

Umstad, M. P., Hale, L., Wang, Y. A., \& Sullivan, E. A. (2013). Multiple deliveries: The reduced impact of in vitro fertilization in Australia. Australian and New Zealand Journal of Obstetrics and Gynaecology, 53, 158164. 